\title{
Modelling the Dynamic Line Parameter of 25 kV AC Railway Electric Traction Lines at Earth Cuttings
}

\author{
Ravi kumaran Nair.C ${ }^{\# 1}$, Devender Kumar Saini*2 ${ }^{*}$ Jayaraju.M ${ }^{\# 3}$ \\ ${ }^{\# 1}$ Part-Time Research Scholar, PhD Engg. (Power). \\ University of Petroleum \& Energy Studies, Dehradun, India \\ nair.ravikumar@rediffmail.com \\ ${ }^{* 2}$ Asst. Prof. Dept of Electrical, Power \& Energy, College of Engineering Studies, \\ University of Petroleum \& Energy Studies, Dehradun, India, \\ dksaini@ddn.upes.ac.in \\ ${ }^{\# 3}$ (Former Director, Agency for Non-conventional Energy and Rural Technology, \\ Ministry of Power, Govt of Kerala), India, \\ jayarajum@gmail.com
}

\begin{abstract}
Modern electric traction lines are mostly of $25 \mathrm{kV} 50 \mathrm{~Hz}$ or $60 \mathrm{~Hz}$ systems. Shunt admittance exists between earth and traction lines are considered to be uniformly distributed all along their length, and are conveniently neglected from calculations \& design of the protection schemes. Fault distance locating algorithms are also designed accordingly. Railway tracks in suburban area shall generally be laid on plane surface and be electrified. However, in developing countries, the railway tracks are electrified at non-suburban areas also to a large extent, where tracks are laid through earth cuttings, tunnels, etc. Analysis on historical data collected from a real traction lines network from a non-suburban area where railway tracks are laid through earth cuttings and tunnel revealed that the parasite capacitance between $25 \mathrm{kV} 50 \mathrm{~Hz}$ AC traction lines and the earth significantly varies with varying topographical features. Data collected and analyses from the experimental setup, and the validation tests conducted thereon on the real traction line system are summarized in this paper.
\end{abstract}

Key words: AC electric traction, Angle of cutting, Base width of cuttings, Over Head Equipment (OHE), Parasite capacitance, Varying profiles.

\section{INTRODUCTION}

Traction Electrification System provides electrical power to the trains by means of; Traction Power Supply System, that includes Traction Sub Stations (TSS) located along the railway track at theoretically equal distance; Traction Power Distribution System (also called as Over Head Equipments or OHE) that is fed at single end consists of conventional catenary system; running rails, and various bonds to the ground (earth). Modelling of $\mathrm{AC}$ power line of railway traction is done at par with the short length AC power transmission line [1] [3]. Impedance $(Z)$ of short length power transmission lines (of length $80 \mathrm{~km}$ or lesser, and with voltage $66 \mathrm{kV}$ or below) comprise an inductive reactance $(\mathrm{jX})$ in series with line resistance $(\mathrm{R})$ per unit length as shown in Fig.1. The effect of shunt admittance exiting between power line and the earth is assumed to be insignificant.

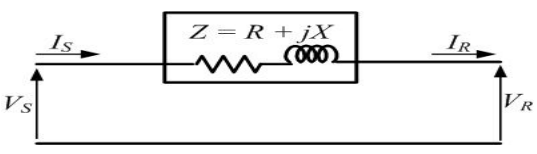

Fig.1 Generalized model of short AC power transmission line

The traction line parameters per unit length resistance, inductance, and capacitance are $R_{0}, L_{0}$ and $C_{0}$, where $\mathrm{R}_{0}$ is 0.1 to $0.3 \Omega / \mathrm{km}, \mathrm{L}_{0}$ is 1.4 to $2.4 \mathrm{mH} / \mathrm{km}$ and, $\mathrm{C}_{0}$ is 10 to $14 \mathrm{nF} / \mathrm{km}$ [6]. The algorithms made for fault distance calculated by the Distance Protection Relay (DPR) in $25 \mathrm{kV}$ AC electric traction line based on the theories [8] [9] [10] of loop impedance of OHE. In all the cases, the impedance angle of OHE is taken as constant; ie $\left\llcorner 70^{\circ}\right.$, and the impedance is considered to be uniformly distributed [2]. Fault distance indicated by the DPR has a vital role in determining the degree of reliability of electrified railway transportation system. In a study [10] made on the behaviours of a real $25 \mathrm{kV} 50 \mathrm{~Hz}$ AC electric railway traction lines while earth fault occurred on them, it was revealed that the generalized model (Fig.1) can't be fit as it is on AC power high voltage traction lines for developing the algorithm for pin pointing the earth fault on it. The topography at the proximity of OHE can significantly influence on the accuracy of the fault distance locating algorithms.

The angle of the earth faults current, however, is determined by the angle of loop impedance of OHE. If it varies; the distance indicate by the DPR shall also vary with a slight margin, may in terms of few hundreds of meters only. But, those erratic data originate by the Distance Protection Relay on the distance of persisting 
earth fault on traction power systems shall cause inordinate delay in detecting them, which in turn shall lead to prolonged supply disruption of train traffic at a wide region. Hence, foolproof algorithms developed duly formulating the variations of the shunt admittance between OHE and earth at various topographical conditions is essential for pinpointing the exact position of earth fault on railway electric traction line. It is obvious that the shut admittance contributed by the parasite capacitance exists between the OHE and earth depends on the height of OHE from rail level, area of the earth cuttings available at the proximity of the OHE, the base width of the earth cuttings, the angle of the cuttings etc.. However, in the available formula [1] the shunt admittance is calculated by presuming the ground below the power line is flat and wide. But the OHE has many unique features, such as, its altitude is as low as $4.58 \mathrm{M}$ from the ground (rail level), and slope profiling (earth cuttings) made through hillocks to lay railway tracks, with slanting height varies from few centimetres to $18 \mathrm{M}$ covers the OHE from three sides. Besides, the earth cuttings may be present within 3 to $5 \mathrm{M}$ radial distances of OHE for a very long stretch. Hence, the data collections from the experiments conducted on model and the validation test conducted on an actual OHE system are adopted as the methodology.

\section{EXPERIMENTAL STUDIES}

Experimental studies were conducted in two steps,

\section{A. Data collection}

Experiments conducted on the similitude model of OHE set up at laboratory (fig.2) for data collection on the parasite capacitance exists between OHE and earth cuttings, for different angles and different base widths of it at the proximity of OHE, keeping the height of OHE and earth cutting controlled. Readings are given in Table 1. Since the standard angles of earth cuttings in railway systems are $30^{\circ}$ for ordinary soil, $45^{\circ}$ for laterite, $76^{\circ}$ for rocks, and $90^{\circ}$ for concrete walls in actual, those are highlighted in bold in the tables 1 . In all the cases, the slanting height of earth cutting is kept as $7.8 \mathrm{M}$ and height of lower conductor OHE is kept as $5.6 \mathrm{M}$, as the controlled variables.

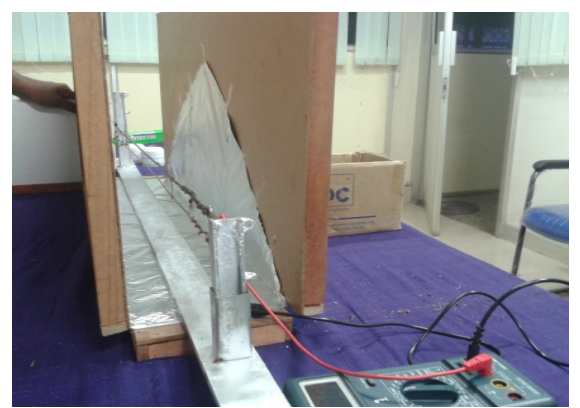

Fig.2. Experimentation on similitude of OHE at laboratory at different angles and different base widths.

TABLE.1. Parasite capacitance between OHE and earth at cuttings, for various base widths and angles

\begin{tabular}{|c|c|c|c|c|c|c|c|c|}
\hline \multirow{2}{*}{$\begin{array}{l}\text { Angle of } \\
\text { cutting in } \\
\text { Degree }\end{array}$} & \multicolumn{7}{|c|}{ Parasite capacitance between OHE and earth at cuttings with base widths, } \\
\cline { 2 - 9 } & $\mathbf{6 . 1 6} \mathbf{M}$ & $\mathbf{6 . 7 2} \mathbf{M}$ & $\mathbf{7 . 2 8} \mathbf{M}$ & $\mathbf{7 . 8 4} \mathbf{M}$ & $\mathbf{8 . 4} \mathbf{M}$ & $\mathbf{8 . 9 6} \mathbf{M}$ & $\mathbf{9 . 5 2} \mathbf{~ M}$ & $\mathbf{1 0 . 0 8} \mathbf{~ M}$ \\
\hline 10 & 14.47 & 14.44 & 14.42 & 14.42 & 14.41 & 14.40 & 14.40 & 14.40 \\
\hline 20 & 14.55 & 14.51 & 14.48 & 14.46 & 14.46 & 14.46 & 14.45 & 14.44 \\
\hline $\mathbf{3 0}$ & $\mathbf{1 4 . 6 3}$ & $\mathbf{1 4 . 5 9}$ & $\mathbf{1 4 . 5 5}$ & $\mathbf{1 4 . 5 3}$ & $\mathbf{1 4 . 5 1}$ & $\mathbf{1 4 . 5 0}$ & $\mathbf{1 4 . 4 8}$ & $\mathbf{1 4 . 4 6}$ \\
\hline 40 & 14.75 & 14.72 & 14.66 & 14.64 & 14.60 & 14.54 & 14.50 & 14.46 \\
\hline $\mathbf{4 5}$ & $\mathbf{1 4 . 8 3}$ & $\mathbf{1 4 . 7 7}$ & $\mathbf{1 4 . 7 4}$ & $\mathbf{1 4 . 7 0}$ & $\mathbf{1 4 . 6 5}$ & $\mathbf{1 4 . 6 0}$ & $\mathbf{1 4 . 5 3}$ & $\mathbf{1 4 . 4 6}$ \\
\hline 50 & 14.92 & 14.85 & 14.81 & 14.75 & 14.69 & 14.64 & 14.56 & 14.47 \\
\hline 60 & 15.09 & 15.04 & 14.96 & 14.89 & 14.82 & 14.73 & 14.62 & 14.51 \\
\hline 70 & 15.38 & 15.31 & 15.21 & 15.10 & 14.98 & 14.85 & 14.70 & 14.53 \\
\hline $\mathbf{7 6}$ & $\mathbf{1 5 . 5 6}$ & $\mathbf{1 5 . 4 5}$ & $\mathbf{1 5 . 3 4}$ & $\mathbf{1 5 . 2 3}$ & $\mathbf{1 5 . 1 0}$ & $\mathbf{1 4 . 9 5}$ & $\mathbf{1 4 . 7 6}$ & $\mathbf{1 4 . 5 5}$ \\
\hline 80 & 15.83 & 15.70 & 15.56 & 15.43 & 15.28 & 15.10 & 14.87 & 14.60 \\
\hline $\mathbf{9 0}$ & $\mathbf{1 6 . 2 5}$ & $\mathbf{1 6 . 1 1}$ & $\mathbf{1 5 . 9 8}$ & $\mathbf{1 5 . 8 1}$ & $\mathbf{1 5 . 6 5}$ & $\mathbf{1 5 . 4 3}$ & $\mathbf{1 5 . 1 0}$ & $\mathbf{1 4 . 6 8}$ \\
\hline
\end{tabular}




\section{B. Validation test}

Parasite capacitance exits between the actual OHE and the earth cuttings were measured (fig.3) for verifying the accuracy of data collected from the experimentation

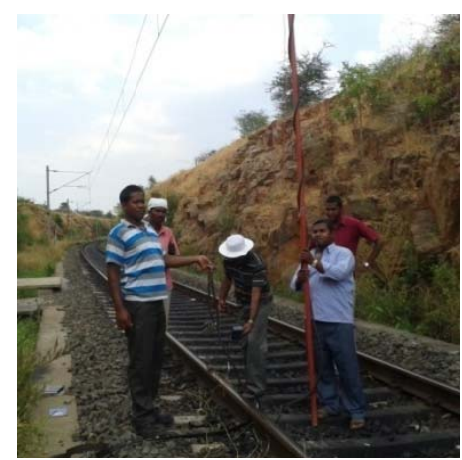

Fig.3. Validation test on an actual OHE at earth cutting.

\section{RESULTS AND ANALYSIS}

Figures 4 to 8 are the plots obtained through the regression analysis made on the parasite capacitances of $25 \mathrm{kV} \mathrm{AC}$ traction line with the earth at varying profiles of earth cuttings, with the help of an online statistical tool [11]. $\mathrm{Y}$ axis represents the parasite capacitance measured, in nano farad / kilo metre $(\mathrm{nF} / \mathrm{kM})$, and $\mathrm{X}$ axis represents the base width of earth cutting, in metre (M)

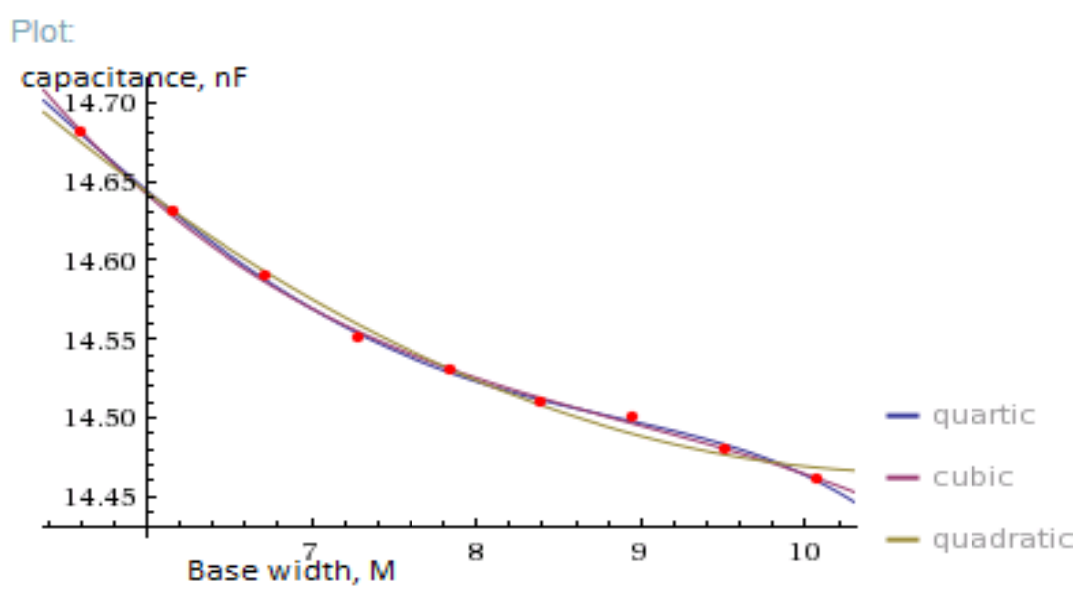

Fig 4. Plot on the parasite capacitances of OHE run through at a 30 degree earth cutting, for different widths of it, at controlled height of earth cutting height \& OHE,

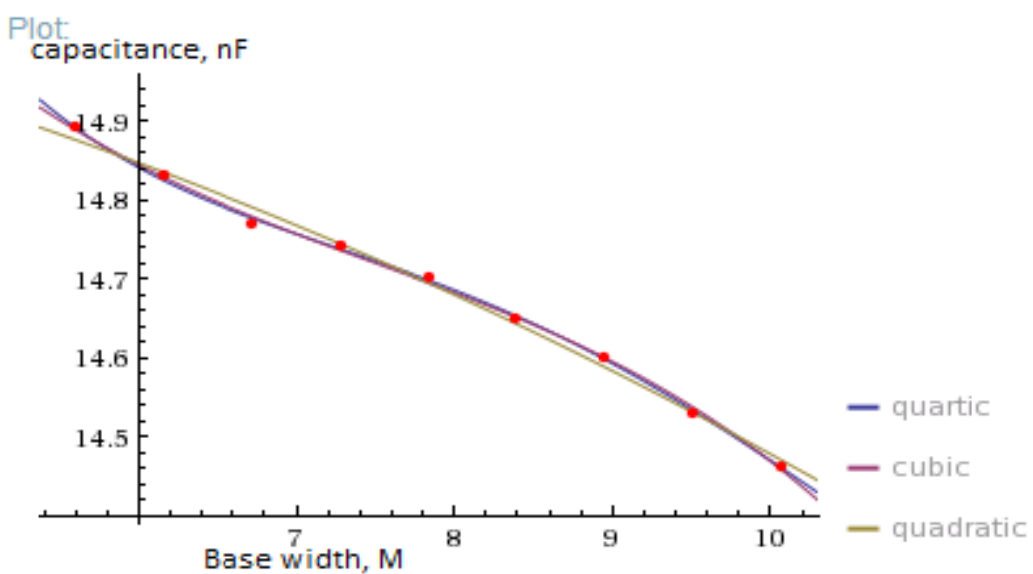

Fig 5. Plot on the parasite capacitances of OHE run through at a 45 degree earth cutting, for different widths of it, at controlled height of earth cutting height \& OHE, 


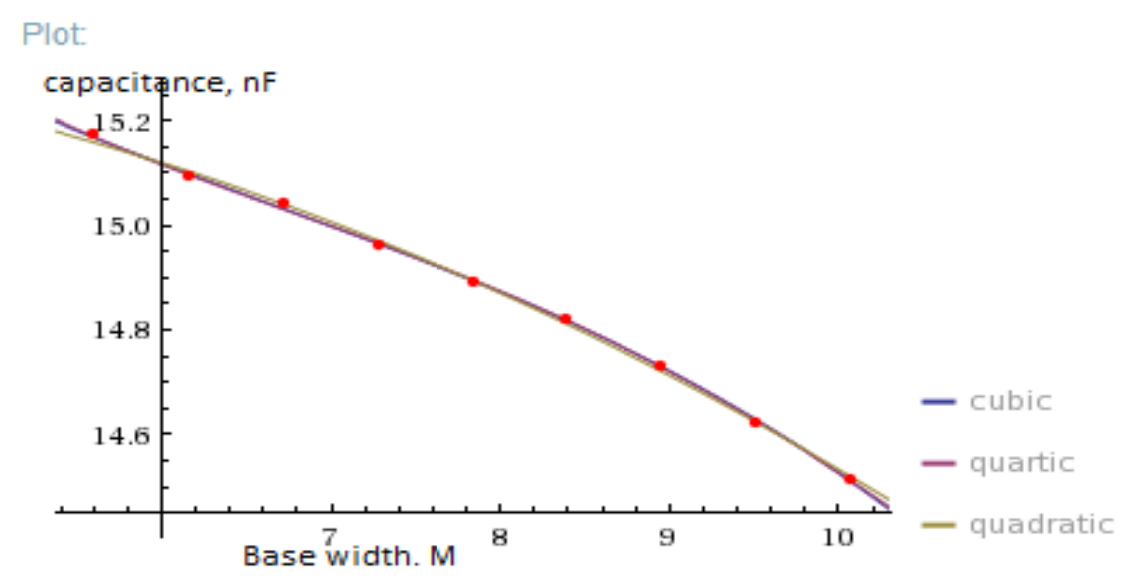

Fig 6. Plot on the parasite capacitances of OHE run through at a 60 degree earth cutting, for different widths of it, at controlled height of earth cutting height \& OHE,

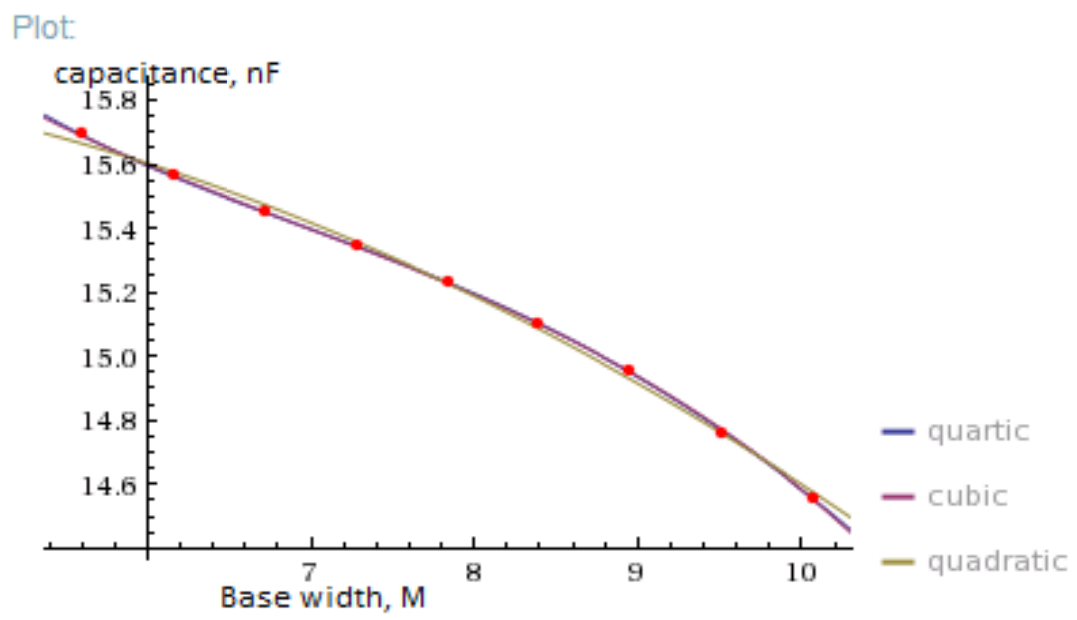

Fig 7. Plot on the parasite capacitances of OHE run through at a 76 degree earth cutting, for different widths of it, at controlled height of earth cutting height \& OHE,

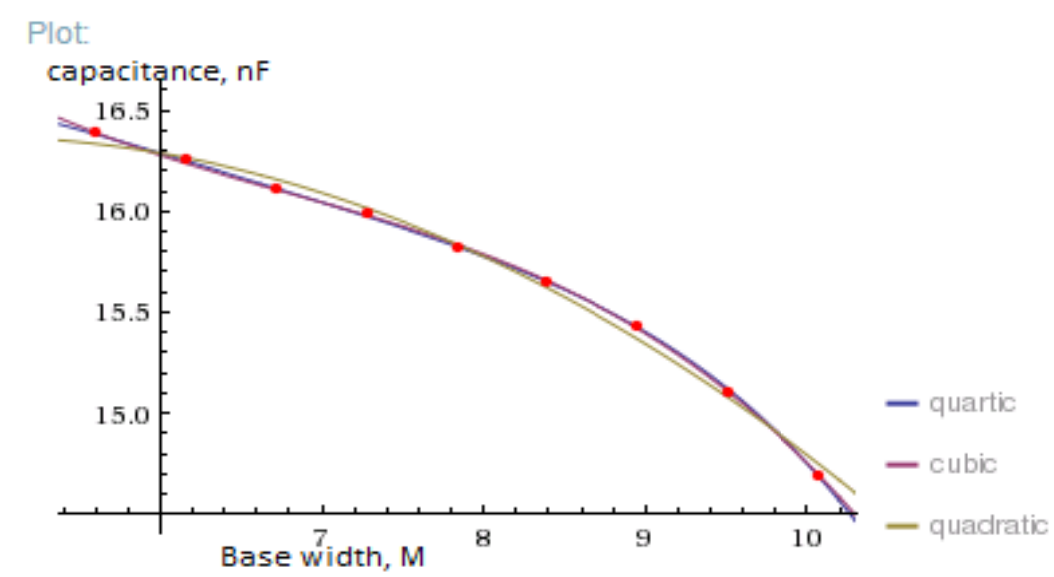

Fig 8. Plot on the parasite capacitances of OHE run through at a 90 degree earth cutting, for different widths of it, at controlled height of earth cutting height \& OHE,

In the regression analysis done with the same online statistical tool [11], non-linear equations, viz. quartic, cubic and quadratic with approximate fit to the curves are also generated by the for different angles of cuttings, viz. $30^{\circ}, 45^{\circ}, 76^{\circ}$ and $90^{\circ}$ whose widths varies from $5.6 \mathrm{M}$ to $10 . .08 \mathrm{M}$. Keeping the height of cutting, and the height of contact wire of $\mathrm{OHE}$ controlled at 7.8 $\mathrm{M} \& 5.6 \mathrm{M}$ respectively. The equations generated are,

Quartic, $\quad \mathrm{Y}=\mathrm{a} \mathrm{X}^{4}+\mathrm{b} \mathrm{X}^{3}+\mathrm{c} \mathrm{X}^{2}+\mathrm{dX}+\mathrm{k}$ 
Cubic, $\quad \mathrm{Y}=\mathrm{aX} \mathrm{X}^{3}+\mathrm{b} \mathrm{X}^{2}+\mathrm{cX}+\mathrm{k}$

Quadratic,

$$
\mathrm{Y}=\mathrm{ax}^{2}+\mathrm{bX}+\mathrm{k}
$$

Where $\mathrm{Y}$ is the parasite capacitance in nano-farad per kilometre $(\mathrm{nF} / \mathrm{kM}), \mathrm{a}, \mathrm{b}, \mathrm{c} \& \mathrm{~d}$ are the coefficients of different powers of the independent variable $\mathrm{X}$, and $\mathrm{k}$ is the constant term ( $\mathrm{Y}$ intercept). $\mathrm{X}$ is the width of earth cutting in metre (M). Equations are shown in tables $2,3 \& 4$.

TABLE 2. Equations generated in Quartic form.

\begin{tabular}{|l|l|l|l|l|c|}
\hline Angle of cut & Coef. of $\mathbf{X}^{\mathbf{4}}$ & Coef.. of $\mathbf{X}^{\mathbf{3}}$ & Coef. of $\mathbf{X}^{\mathbf{2}}$ & Coef. of X & $\mathbf{k}$ \\
\hline $30^{0}$ & -0.0008 & +0.218 & -0.216 & +0.816 & +13.8 \\
\hline $45^{0}$ & +0.0011 & -.0391 & +0.506 & -2.881 & -20.9 \\
\hline $76^{0}$ & +0.001 & -0.039 & +0.536 & -3.235 & +22.9 \\
\hline $90^{0}$ & -0.0036 & +0.093 & -0.908 & +3.723 & +11.2 \\
\hline
\end{tabular}

TABLE 3. Equations generated in Cubic form

\begin{tabular}{|l|l|l|l|l|}
\hline Angle of cut & Coef. of $\mathbf{X}^{\mathbf{3}}$ & Coef. of $\mathbf{X}^{\mathbf{2}}$ & Coef. of X & $\mathbf{k}$ \\
\hline $30^{0}$ & -0.0024 & +0.0645 & -0.606 & +16.476 \\
\hline $45^{0}$ & -0.0043 & +0.097 & -0.801 & +17.09 \\
\hline $76^{0}$ & -0.0032 & +0.0633 & -0.541 & +16.767 \\
\hline $90^{0}$ & -0.0189 & +0.385 & -2.842 & +23.544 \\
\hline
\end{tabular}

TABLE.4. Quadratic equations generated.

\begin{tabular}{|l|l|l|l|}
\hline Angle of cut & Coef. of $\mathbf{X}^{\mathbf{2}}$ & Coef. of $\mathbf{X}$ & $\mathbf{k}$ \\
\hline $30^{0}$ & +0.0081 & -0.173 & +15.391 \\
\hline $45^{0}$ & -0.0044 & -0.022 & +15.137 \\
\hline $76^{0}$ & -0.0218 & +0.0979 & +15.799 \\
\hline $90^{0}$ & -0.059 & +0.5699 & +14.99 \\
\hline
\end{tabular}

The Akaike Information Criterion (AIC) [4], the Bayesian Information Criterion (BIC) [5], the $\mathrm{R}^{2}$ (coefficient of determination in regression analysis) and the adjusted $R^{2}\left(\operatorname{adj} . R^{2}\right.$ ) are also calculated for all those equations separately, and shown in tables 5,6 and 7.

TABLE 5. AIC, BIC, $\mathrm{R}^{2}$ and adj. $\mathrm{R}^{2}$ for Quartic equations for various angles of earth cutting

\begin{tabular}{|l|c|c|c|l|}
\hline Angle of cut & AIC & BIC & $\mathbf{R}^{\mathbf{2}}$ & (adj.R $^{\mathbf{2}}$ ) \\
\hline $30 \mathrm{deg}$ & -74.49 & -73.30 & 0.999 & 0.998 \\
\hline $45 \mathrm{deg}$ & -64.40 & -63.21 & 0.999 & 0.998 \\
\hline $76 \mathrm{deg}$ & -74.31 & -73.12 & 0.999 & 0.999 \\
\hline $90 \mathrm{deg}$ & -51.53 & -50.34 & 0.999 & 0.999 \\
\hline
\end{tabular}

TABLE 6. AIC, BIC, $\mathrm{R}^{2}$ and adj. $\mathrm{R}^{2}$ for Cubic equations for various angles of earth cutting

\begin{tabular}{|l|r|r|l|l|}
\hline Angle of cut & AIC & BIC & $\mathbf{R}^{2}$ & (adj.R $^{\mathbf{2}}$ \\
\hline $30 \mathrm{deg}$ & -70.45 & -69.47 & 0.998 & 0.997 \\
\hline $45 \mathrm{deg}$ & -61.81 & -60.83 & 0.999 & 0.998 \\
\hline $76 \mathrm{deg}$ & -67.70 & -66.71 & 0.999 & 0.999 \\
\hline $90 \mathrm{deg}$ & -44.97 & -43.98 & 0.999 & 0.999 \\
\hline
\end{tabular}


TABLE 7. AIC, BIC, $\mathrm{R}^{2}$ and adj. $\mathrm{R}^{2}$ for Quadratic equations for various angles of earth cutting

\begin{tabular}{|l|r|r|l|l|}
\hline Angle of cut & AIC & BIC & $\mathbf{R}^{2}$ & (adj.: $^{2}$ ) \\
\hline 30 deg & -58.61 & -57.82 & 0.992 & 0.989 \\
\hline 45 deg & -48.42 & -47.63 & 0.993 & 0.991 \\
\hline 76 deg & -38.48 & -37.69 & 0.997 & 0.996 \\
\hline 90 deg & -22.98 & -22.19 & 0.993 & 0.991 \\
\hline
\end{tabular}

\section{CONCLUSION}

In the regression analysis done on all sets of data for all the different conditions, the coefficient of determination $\mathrm{R}^{2}$, and the adjusted $\mathrm{R}^{2}$ are found more than 0.9 (which decides the minimum acceptance level of curve fittings) for all the three forms of equations. However, the highest $\mathrm{R}^{2}$ is obtained in the quartic equations, which shall give highest accuracy if utilized in creating fault locating algorithm. But the complexity in resolving the higher degree equations may make the software programming costlier in the software controlled numeric fault locating relays. The quadratic equations are also having very high $\mathrm{R}^{2}$ value, in the order of 0.99 and above. In the validation test conducted on the actual OHE system at earth cutting with base width 8.4 metre, height 7.9 metre, and angle of cutting $76^{\circ}$, the parasite capacitance of OHE of length 1234.2 metre was measured as 18.67 $\mathrm{nF}$, which is equivalent to $15.1279 \mathrm{nF} / \mathrm{kM}$ The parasite capacitance value calculated using the newly formed quadratic equation (3) for the earth cutting with all the measurements similar to the above is,

Parasite capacitance, $\mathrm{Cp}=-0.0218 \mathrm{X}^{2}+0.0979 \mathrm{X}+15.799=15.08316 \mathrm{nF} / \mathrm{kM}$

The variation of calculated value from the value obtained in the validation test is less than $1 \%$. This much of variation may contribute the error in the fault distance locating algorithm by few metres only. The variation in the accuracy of pin pointing the fault location on OHE within 100 metre range is generally tolerable by electric traction departments of railway organizations. Hence, using of quadratic equations for finding the parasite capacitance existing between OHE and the earth cuttings is equally recommendable to create algorithms for pin pointing the fault location on OHE.

\section{ACKNOWLEDGEMENT}

The authors express their sincere thanks to the Trivandrum Divisional Administration of Southern Railway for allowing to switch off the $25 \mathrm{kV}$ Electrical Traction lines without affecting the train services, many times, for measuring the parasite capacitances of OHE at different topographical conditions, as the part of the validation tests.

\section{REFERENCES}

[1] M.V.Deshpande, "Electrical Power System Design”, Tata McGraw Hill, New Delhi. 1984

[2] "AC Traction Manual for Indian Railways", vol.II, Part-II., pp 101, 1993

[3] A.R.Bergan and V.Vittal, "Power System Analysis", Pearson Edu. Asia, New Delhi, 2001

[4] Pan, W. "Akaike's information criterion in generalized estimating equations", Biometrics 57: 120-125, 2001

[5] Roderick D. Ball, “Approximate Analysis Using the Bayesian Information Criterion”, GENETICS vol. 159 no. 3 1351-1364, 2001

[6] Mariscotti.A., Pozzobon.P, "Synthesis of line impedance expressions for Railway traction system", IEEE Trnas. Vehicular Technol. Vol 52, pp 420 - 430, 2003

[7] Cheng.W., Xu.G., and Mu.L, "A novel fault location algorithm for traction network based on distributed parameter line model", Proceedings. CSU - EPSA, Vol 17, pp 66-63, 2005

[8] Lin.X., Weng.H., and Wang.B.A., "A generalized method to improve the location accuracy of the single- ended sampled data and lumped parameter model based fault locators", Electrical Power Energy System, vol 31, pp 201- 205, 2009

[9] Yimin Zhou., Guoquing Xu., Yanfeng Chen, "Fault Location in Power Electrical Traction Line System", Energies Journal, pp.5004, 5005, Nov.2012

[10] Ravi kumaran Nair. C., Devendar Saini. and Jayaraju.M, "Effect of Topography at the Proximity of AC Electric Traction Line on the Earth Fault Distance Locating Algorithm", International Journal of Applied Engineering Research”, Vol 11, Number 1, pp 113-118, 2016

[11] www.wolframalpha.com 